\title{
Ensino Médio Técnico em Agroecologia e resistência no campo: o caso da Escola 25 de Maio, Fraiburgo (SC)
}

\author{
Angélica Kuhn ${ }^{1}$ \\ ${ }^{1}$ Universidade de São Paulo - USP, Faculdade de Educação, Avenida da Universidade, 308, São Paulo, Brasil. \\ angelicakuhn@gmail.com
}

RESUMO. O artigo aborda os desafios do Ensino Médio que integra educação e trabalho no contexto da Educação do Campo. Este tema é parte da pesquisa de mestrado que analisou o Curso de Ensino Médio Técnico em Agroecologia da Escola do Campo 25 de Maio, localizada no Assentamento Rural Vitória da Conquista, Fraiburgo (SC). O estudo utilizou a metodologia de pesquisa qualitativa a partir de questionário aplicado a egressos de uma das turmas formadas pela escola e entrevistas com quatro egressos a fim de evidenciar como eram praticados os princípios pedagógicos e filosóficos do Projeto Político Pedagógico (PPP) na escola. Os resultados evidenciaram que existe coerência entre os princípios e as práticas construídas e vivenciadas pelos estudantes, com destaque para: a gestão democrática; a articulação entre educação, trabalho e cultura; a participação nos movimentos sociais como elemento formativo; a agroecologia como parte de um projeto de campo pautado na relação sustentável entre ser humano e natureza; a estreita relação entre família e escola e o vínculo entre teoria e prática.

Palavras-chave: Agroecologia, Agronegócio, Educação do Campo, Ensino Médio. 


\title{
High School Course Integrated with Technical Professional Educational in Agroecology and resistance of countryside, the case of 25 de Maio School, Fraiburgo (SC)
}

\begin{abstract}
The article discusses the high school education challenges that integrates education and work in the context of Rural Education. This theme is part of the master degree research that analyzed the High School course integrated with technical professional educational in Agroecology of the School 25 de Maio, located in the rural community of Vitória da Conquista, Fraiburgo/SC. The study used qualitative research methodology by applying a questionnaire to one of the graduates class of the school and interviews with four graduates in order to evidence the practice of the pedagogical and philosophical principles of the school Political Pedagogic Project (PPP). The results demonstrated that there is coherence between the principles and practices built and lived by the students, especially when it relates to: democratic direction; the relationship between education, work and culture; the participation in social movements as a formative element; the agroecology as part of a countryside project based on sustainable relationship between humans and nature; the close relationship between family and school and the link between theory and practice.
\end{abstract}

Keywords: Agroecology, Agribusiness, Rural Education, High School. 


\section{Curso Técnico en Agroecología y la resistencia en el campo: el caso de la Escuela 25 de Mayo de Fraiburgo (SC)}

RESUMEN. El artículo analiza los desafíos de la escuela secundaria que integra la educación y el trabajo en el contexto de la educación rural. Este tema es parte de la investigación del máster que analizó lo Curso Técnico en Agroecología de la Escuela 25 de Mayo, ubicado en la zona rural de Vitoria da Conquista, Fraiburgo (SC). Metodológicamente la investigación utilizó la investigación cualitativa a partir de un cuestionario aplicado a los graduados de uno de los grupos formados por dicha escuela y entrevistas con cuatro graduados con el fin de mostrar cómo se practicaban los principios pedagógicos y filosóficos del proyecto político pedagógico en la escuela. Los resultados mostraron que existe coherencia entre los principios filosóficas y pedagógicos y las prácticas construidas y experimentadas por los estudiantes, en especial: la gestión democrática; la relación entre la educación, el trabajo y la cultura; participación en movimientos sociales como un elemento formativo; agroecología como parte de un proyecto de campo basado en la relación sostenible entre los seres humanos y la naturaleza; la estrecha relación entre la familia y la escuela y el vínculo entre la teoría y la práctica.

Palabras-clave: Agroecología, Agroindustria, Educación Rural, Ensino Secundario. 


\section{Introdução}

O presente artigo aborda estudo de caso sobre a Escola 25 de Maio realizado no mestrado. $\mathrm{O}$ interesse pelo tema surgiu da experiência vivenciada no Movimento dos Trabalhos Rurais Sem Terra (MST) e das experiências posteriores a partir do trabalho em uma ONG, fazendo formação de professores em diferentes Estados do Brasil, atividade que me proporcionou um olhar panorâmico sobre a realidade da educação brasileira.

O ímpeto de estabelecer comparação entre a experiência vivenciada no MST e as realidades que conheci era imediato. Com frequência ouvia-se de gestores locais que "os alunos do meio rural davam muito trabalho", que se pudessem "fechariam todas as escolas existentes no campo", entre outros comentários que menosprezavam e excluíam essa população do direito à educação. $\mathrm{O}$ oposto do que vi no MST, movimento social que luta por um conjunto de políticas públicas que caracterizam processos de Reforma Agrária, entre elas o acesso à educação de qualidade, que guarda identidade com as lutas histórias do campo e lança perspectivas para o meio rural, que engloba a relação campo-cidade a partir de parâmetros sustentáveis na relação com a natureza e entre os seres humanos.
Era, no entanto, uma diferença espantosa em relação à falta de qualidade, evasão, falta de compromisso dos gestores, precariedade da formação dos professores e das condições de trabalho, que pude observar de perto nos locais que conheci pelo Brasil a fora, na cidade e no campo. Do ponto de vista acadêmico, considero fundamental buscar experiências que evidenciem práticas pedagógicas na direção da superação das desigualdades, apontando avanços e desafios de tais experiências. Penso que este é um acúmulo importante de resistência diante do cenário atual.

Foi assim que surgiu o interesse pelo estudo de caso da Escola 25 de Maio, localizada no Assentamento Vitória da Conquista, Fraiburgo, no Estado de Santa Catarina, especificamente o Ensino Médio, pois esse segmento era o que apresentava mais dificuldade em se organizar ou mesmo existir na maioria das localidades que conheci.

A Escola do Campo 25 de Maio faz parte da luta do MST pela democratização da educação escolar, pertence a um conjunto de 46 escolas localizadas em áreas de assentamentos rurais no Estado de Santa Catarina, as quais totalizam 3.567 alunos, de acordo com dados fornecidos pelo Setor de Educação do MST. 
O nome da Escola demonstra sua identidade com o MST, pois faz referência ao dia 25 de maio de 1985, quando ocorreu a primeira grande ocupação de terras em Santa Catarina, no município de Abelardo Luz, com a participação de 2.000 famílias. Assim como nos demais assentamentos rurais conquistados pelo MST, umas das primeiras preocupações das famílias assentadas foi o acesso à escola para seus filhos. Mesmo sem a infraestrutura adequada, desde o início do assentamento, as crianças tiveram acesso à educação escolar. Em 1987, foram criadas duas escolas de Ensino Fundamental. A expansão dos níveis de ensino, como a abertura de turmas de Ensino Médio no próprio assentamento, sempre foi uma reivindicação das famílias assentadas.

Finalmente, em 2004, foi criado o Ensino Médio, a fim de atender estudantes de diversas áreas de assentamentos do Estado de Santa Catarina, que por algum motivo não estavam estudando em seus assentamentos de origem, ou interessados na proposta da escola. Desde então, estes jovens permanecem alojados na escola durante um período e participam da sua organização interna e, em período alternado, em seus assentamentos, através da Pedagogia da Alternância.

O que chama a atenção é a capacidade organizativa dos movimentos sociais para a garantia do direito à educação, a denotar o fato de que o curso de Ensino Médio em Agroecologia da Escola 25 de Maio teve início antes mesmo de ser aprovado pelos órgãos oficiais. A partir da constatação de que havia demanda para o segmento sem atendimento pela Secretaria Estadual de Educação, aproximadamente 40 alunos, à época, que não tinham dado continuidade aos estudos no Ensino Médio, foi realizada uma etapa preparatória com uma turma composta por vinte alunos, quinze de assentamentos locais e cinco de outras regiões do Estado de Santa Catarina. A Coordenação da turma ficou por conta do MST e da comunidade local, que desenvolveram diversas estratégias para a manutenção da turma. Cinco famílias receberam os alunos de fora do município, os assentados e a Cooperativa de Produção da Região do Contestado (Coopercontestado) arcaram com a alimentação, esta última efetuou também um empréstimo financeiro para as demais despesas, além de ceder o espaço de uma agroindústria, localizada na área da escola, para a realização das aulas, ministradas pelos professores do MST. Diante da demanda, o Ensino Médio se torna, provisoriamente, uma extensão da escola urbana (Mohr \& Mohr, 2007). 
Com o passar do tempo, a reivindicação dos assentados foi por um curso técnico em agroecologia de nível médio, que não foi atendida pelas redes municipal e estadual. Dessa forma, a elaboração da proposta passa para o Programa Nacional de Educação para a Reforma Agrária (PRONERA), um programa nacional voltado para as áreas de Reforma Agrária que envolve o Estado e os movimentos sociais na elaboração e execução de projetos voltados para os assentamentos (Freitas, 2011).

Assim, o Curso Técnico em Agroecologia da Escola 25 de Maio teve início oficialmente em 2005 com 51 alunos. O curso foi estruturado para ter a duração de três anos, com uma carga horária total de 1.680 horas/aula distribuídas da seguinte forma: Tempo Escola com 1.440 horas e Tempo Comunidade, 240 horas. As atividades desenvolvidas pelos alunos nos assentamentos de origem e/ou local de trabalho contaram como Tempo Comunidade (Freitas, 2011).

Para a certificação relacionada à formação técnica em agroecologia firmouse uma parceria com a Escola Agrotécnica Federal de Rio do Sul, que, além de certificar, cedeu professores das disciplinas técnicas. Além disso, o PRONERA possibilitou a contratação de dois professores das Ciências Agrárias. A Escola contava ainda com a participação de profissionais da equipe técnica do Setor de Produção do MST e professores convidados da Universidade Federal de Santa Catarina (Mohr \& Mohr, 2007).

O MST ficou com a maior responsabilidade, contribuindo com as despesas referentes a material pedagógico, deslocamento de alunos, alimentação, visitas pedagógicas realizadas às famílias dos alunos durante o Tempo Comunidade. Portanto, a pouca infraestrutura deste movimento impunha certas limitações ao pleno desenvolvimento da proposta.

O Ensino Médio geral ficou subordinado ao sistema estadual de educação, funcionando como extensão de uma escola urbana, com educadores que já atuavam na Escola 25 de Maio e outros que completariam as vagas. Somente em 2009 a Secretaria Estadual de Educação assume finalmente a responsabilidade pelo segmento, com a denominação de Ensino Médio Integrado à Educação Profissional Técnico em Agroecologia, autorizado a funcionar pelo Parecer 455/08. Se por um lado, os assentados viam o direito atendido, por outro, Secretaria Estadual não supre totalmente as necessidades para o seu pleno desenvolvimento, como suporte para alimentação, para as visitas dos professores às famílias dos alunos no 
Tempo Comunidade, uma das mais importantes atividades da proposta. Isso demonstra os desafios enormes a serem superados para o atendimento de propostas que guardam especificidades em relação aos tempos, espaços e currículo.

Atualmente, atuam duas redes de ensino na escola. As turmas do Ensino Fundamental I e II, as quais funcionam nos períodos matutino e vespertino, estão sob responsabilidade da Rede Municipal de Ensino e o Ensino Médio, que funciona através da Pedagogia da Alternância, pela Rede Estadual de Ensino.

A pesquisa, de cunho qualitativo, foi realizada com 23 egressos, formados na turma de 2009, para os quais foi enviado um questionário. Destes, 22 responderam, sendo 16 do sexo masculino e seis do sexo feminino, e a média de idade entre 22 e 21 anos respectivamente, com duas exceções, um egresso de 24 e um de 28. A escolha de quatro egressos para a entrevista semiestruturada seguiu o critério da disponibilidade dos egressos e jovens com trajetórias diferentes umas das outras. Assim, temos uma egressa que está cursando ensino superior em um dos cursos do MST em parceria com o Programa Nacional de Educação na Reforma Agrária (Pronera) em Universidade Pública; um egresso que migrou para a cidade e dois que vivem e trabalham como técnicos agrícolas em assentamentos rurais de Santa Catarina. O questionário e as entrevistas foram elaborados a partir do Projeto Político Pedagógico com o objetivo de compreender a proposta da escola em relação à trajetória dos alunos quanto à permanência no campo, o trabalho e a continuidade dos estudos e como eram vivenciados os princípios filosóficos e pedagógicos da Escola na prática, tema este abordado no presente artigo.

\section{Contexto da Escola 25 de Maio}

O contexto socioespacial da Escola 25 de Maio é marcado historicamente pela concentração fundiária e pela grilagem de terras, sobre o qual discorremos de forma breve. O nome do município Fraiburgo, foi emprestado da família Frey, a primeira a chegar à região, em 1919. Essa família passa a explorar a madeira, instalando ali uma serraria. Originária da Alsácia, a família Frey abriu as primeiras ruas e construiu uma barragem que deu origem a um lago artificial, o Lago das Araucárias, um dos cartões postais da cidade. A região se desenvolveu rapidamente e se tornou distrito em 1949 e cidade em 1961, desmembrando-se de Videira e Curitibanos (Burke, 1994).

O município é marcado pela monocultura da maçã. Com uma população de 34.555 habitantes, esse número aumenta 
consideravelmente durante o período de safra da maçã (de janeiro a abril), quando cerca de 10.000 trabalhadores vão a Fraiburgo para trabalhar na colheita da fruta, a maioria proveniente da periferia de Curitiba. A economia de Fraiburgo provém principalmente da produção da fruta, o que caracteriza o município como a Terra da Maçã. Fato que se consolida a partir da busca de alternativas econômicas à diminuição da mata nativa, consequência da exploração da madeira. A fruta foi facilmente adaptada ao clima temperado da região, que devido à sua altitude, apresenta baixas temperaturas durante a maior parte do ano, chegando a $-5^{\circ} \mathrm{C}$ no inverno. ${ }^{\mathrm{i}}$

Além da produção de maçãs, predomina a monocultura de pinus, eucalipto e soja, transformando a paisagem originalmente coberta por bosques de Araucária angustifolia, ou popularmente conhecida como Pinheiro-do-Paraná, de Imbuia, Cedro, Canela e Erva-Mate, espécies botânicas naturais da paisagem sulina.

Situando o Ensino Médio em Agroecologia da Escola 25 de Maio: um breve panorama da trajetória do Ensino Médio no Brasil

$\mathrm{Na}$ história da educação brasileira o Ensino Médio se apresenta como a etapa do ensino que mais expressa à contradição entre capital e trabalho, que aparece no falso dilema de sua identidade. "A história nos permite maior clareza sobre a questão, porque vai revelar a ordenação da sociedade em classes que se distinguem pela apropriação da terra, da riqueza que advém da produção social e da distribuição dos saberes" (Frigotto, Ciavata \& Ramos, 2012, p. 31).

Até a década de 1920, a educação era voltada para a formação das elites, com um currículo clássico, voltado para o ensino superior. A "crise de identidade" do Ensino Médio surge com a expansão da escola pública. Nessa época, a formação profissional estava atravessada por um viés assistencialista e servia para a formação do caráter de jovens pobres e órfãos, numa perspectiva moralista e higiênica do trabalho. Para esse fim, foram criadas, em 1909, 19 escolas de artes e ofícios que incluíam o curso rural e o curso profissional com duração de quatro anos, permitindo o acesso a cursos técnicos, nas áreas comercial, agrícola e normal, em nível ginasial e terminal, ou seja, sem possibilidade do estudante avançar para o ensino superior. "Para ilustrar o restrito acesso ao ensino secundário propedêutico, em 1920, um em cada mil habitantes fazia o curso" (Rodrigues, 2010, p. 183).

As transformações ocorridas na década de 1930, com a intensa migração da população do campo para a cidade, com a intensificação do processo de 
industrialização, trouxeram significativas mudanças para a relação entre a educação e as necessidades daquele momento de transformações. Mesmo com a movimentação ocorrida entre os intelectuais brasileiros da década de 1930, que culminou na assinatura do Manifesto dos Pioneiros da Educação Nova, não há uma alteração da estrutura dual da educação marcada por modelos de escola voltados para a formação propedêutica das elites e outra para os trabalhadores.

De acordo com Kuenzer:

Se a divisão social e técnica do trabalho é condição indispensável para a constituição do modo capitalista de produção, à medida que, rompendo com a unidade entre teoria e prática, prepara diferentemente os homens para que atuem em posições hierárquica e tecnicamente diferenciadas no sistema produtivo, deve-se admitir como decorrência natural deste princípio a constituição de sistemas de educação marcados pela dualidade estrutural. No Brasil, a constituição do sistema de ensino não se deu de outra forma (2001, p.12).

Durante o Estado Novo (19371945), as políticas educacionais são influenciadas pela ideologia nacionalista que marca o período. É criada a Reforma Capanema - Decreto $\mathrm{n}^{\mathrm{o}}$ 4.244/42, pelo então Ministro da Educação Gustavo Capanema. A Reforma acaba reforçando o caráter elitista da escola, bem como a dualidade do Ensino Médio, embora as matrículas tenham crescido $81 \%$ entre 1935 e 1940 e, 333\% entre 1945 e 1950. Os dados demonstram um aumento do acesso das classes médias e urbanas à escola (Rodrigues, 2010).

Com a Lei de Diretrizes e Bases $n^{\circ}$ 4024/61, há uma descentralização do currículo e eliminação das restrições do acesso ao ensino superior para os egressos dos cursos profissionalizantes. Contudo, a dualidade não foi alterada. Esse período é marcado pela expansão do acesso ao Ensino Médio, que só entre 1945 e 1960, aumentou o número de matrículas em 296,6\% (Rodrigues, 2010).

Com o Golpe Militar de 1964, o viés autoritário da educação e a forte influência norte-americana deste período têm como ápice sua materialização na revisão da LDB anterior e promulgação da LDB $\mathrm{n}^{\circ}$ 5.692/71, passando por significativas alterações. $\mathrm{O}$ ensino secundário muda sua nomenclatura para $2^{\circ}$ grau, estabelecendo uma profissionalização compulsória e universal. Com o fim da Ditadura Militar e com o processo de redemocratização política, passou-se a se exigir do Ensino Médio mudanças de suas funções.

A promulgação da LDB nº 9394/96 trouxe mudanças significativas para $o$ 
Ensino Médio. Dentre as quais, destaca Rodrigues (2010): o rompimento com a trajetória de equivalência entre os cursos acadêmicos e profissionais do secundário implantada em 1953, caracterizando a educação profissional nos níveis básico, técnico e tecnológico e como alternativa ao ensino superior; a definição do ensino médio como etapa final da educação básica, voltado principalmente para a formação geral do estudante, sua preparação básica para o trabalho e para o exercício da cidadania; a articulação do Ensino Médio e da educação profissional técnica ao conceito de flexibilidade, apontando para a constituição de diferentes trajetórias formativas; a autonomia das escolas na definição dos currículos e na organização do ensino e a aposta em uma proposta de educação tecnológica.

No entanto, um ano após a LDB $\mathrm{n}^{\circ}$ 9394/96 entrar em vigor é estabelecido o Decreto $n^{\circ}$ 2.208/97, ainda no Governo Fernando Henrique Cardoso, representando a negação das conquistas da LDB de 1996. Decreto este que, de acordo com Kuenzer (2006), “(...) teve como principal proposta à separação entre o Ensino Médio e a Educação Profissional, que a partir de então passaram a percorrer trajetórias separadas e não equivalentes". E complementa que, neste período de governo, também ocorreu “(...) a criação do Programa Nacional de Educação na Reforma Agrária
(PRONERA), como política do Ministério de Desenvolvimento Agrário, a partir da mobilização dos trabalhadores do campo em articulação com a universidade" (p.88).

De acordo com Frigotto, Ciavatta e Ramos:
O Decreto n. 2.208/97 e outros instrumentos legais (como a Portaria n.646/97) vêm não somente proibir a pretendida formação integrada, mas regulamentar formas fragmentadas e aligeiradas de educação profissional em função das alegadas necessidades do mercado. O que ocorreu também por iniciativa do Ministério do Trabalho e Emprego, por meio de sua política de formação profissional (2012, p. 25).

No ano de 2004, foi promulgado pelo Presidente da República Luis Inácio Lula da Silva o Decreto n. 5.154/04, objetivando alterações na legislação referente ao Ensino Médio e Profissional, o qual

Com todas as suas contradições é a consolidação da base unitária do ensino médio, que comporte a diversidade própria da realidade brasileira, inclusive possibilitando a ampliação de seus objetivos, como a formação específica para o exercício de profissões técnicas. Daqui por diante, dependendo do sentido em que se desenvolva a disputa política e teórica, o 'desempate' entre as forças progressistas e conservadoras poderá conduzir para a superação do dualismo na educação brasileira ou consolidá-lo definitivamente 
(Frigotto, Ciavata \& Ramos, 2012, p. 37-38).

Como afirmam os autores, o Decreto n. 5.154/04 reestabelece a possibilidade de oferta conjunta, em uma mesma base, da formação geral e profissional, no chamado Ensino Médio integrado. Contudo, a efetivação da proposta depende da articulação no espaço de disputas políticas na sociedade. Em 2009, apenas $2,1 \%$ das matrículas do Ensino Médio correspondiam ao Ensino Médio integrado, evidenciando os muitos desafios para que a integração de fato se torne realidade. Há que se ressaltar que conceitos como educação politécnica e trabalho como princípio educativo são trazidos para o centro do debate em torno de uma nova proposta para o Ensino Médio que avance na unificação entre formação geral e profissional, rompendo com a histórica dualidade deste nível de ensino.

O Ensino Médio Integrado da Escola 25 de Maio caminha nesta direção. É a partir desses sujeitos históricos que hoje lutam pela democratização da terra e de outros direitos como a educação, que estão nascendo e podem nascer experiências que contestem mais radicalmente a lógica social dominante, hegemônica e que recoloquem a perspectiva de construção social da educação para "além do capital". É nesse sentido que se dá a resistência política, econômica e cultural das populações que vivem no e do campo, na luta por outra lógica de trabalho, que não o assalariado e nem a vinculação à agricultura de negócio. Nesse contexto, a agroecologia, abordada no currículo da Escola 25 de Maio, liga-se à justiça social, à soberania alimentar e à cooperação entre os trabalhadores (Caldart, 2008).

Nessa direção o curso de Ensino Médio Integrado da Escola 25 de Maio propõe uma educação emancipadora, tendo como eixo principal a agroecologia, que coloca a discussão da sustentabilidade no debate político e econômico que envolve a questão agrária atual, ao problematizar e evidenciar as contradições existentes no modelo dominante na agricultura, o agronegócio, e como este se coloca na totalidade das contradições sociais.

Em meio a tais contradições, e não sem dificuldades, a Escola 25 de Maio vem construindo desde 2004, um Ensino Médio que ao articular o acesso ao conhecimento científico e o enfrentamento do atual modelo de agricultura, o agronegócio, propõe outras bases tecnológicas para a produção agrícola, a partir da agroecologia, e recoloca a formação humana pensada a partir da articulação entre trabalho e educação no centro da função da escola. 
Ensino Médio Integrado Técnico em Agroecologia na fala de alunos egressos da Escola 25 de Maio

O Projeto Político Pedagógico foi o ponto de partida para a análise da prática educativa da Escola 25 de Maio. Como afirma Alencastro (2009):

(...) o que se espera da escola hoje é uma educação de qualidade, tendo como sustentáculos o projeto político-pedagógico e a gestão democrática (p. 163).

Nesse sentido, buscamos compreender as tensões, conflitos e desafios de uma proposta de ensino médio protagonizada pelos movimentos sociais do campo, construída a partir de princípios filosóficos e pedagógicos que compreendem a educação como parte do processo de transformação social. De acordo com o PPP da Escola 25 de Maio sua prática educativa é norteada por princípios filosóficos que integram trabalho e cooperação, voltada para as várias dimensões da pessoa humana e um processo permanente de formação e transformação humana.

Quanto aos princípios pedagógicos, a Escola 25 de Maio defende em seu Projeto Político Pedagógico a relação entre teoria e prática; a realidade como base da produção do conhecimento; conteúdos formativos socialmente úteis; educação para o trabalho e pelo trabalho; vínculo orgânico entre processos educativos e processos políticos; vínculo orgânico entre processos educativos e processos econômicos; vínculo orgânico entre educação e cultura; gestão democrática; auto-organização dos educandos; criação de coletivos pedagógicos e formação permanente dos educadores/das educadoras; desenvolvimento de habilidades de pesquisa; combinação entre processos pedagógicos, coletivos e individuais; educação voltada à construção da agroecologia.

Nas entrevistas realizadas com os egressos buscamos estabelecer algumas relações entre os princípios filosóficos e pedagógicos do PPP da Escola 25 de Maio com o objetivo de analisar os seus desdobramentos no cotidiano da escola.

A Pedagogia da Alternância é apontada pelos egressos como sendo um dos principais elementos que diferenciam a Escola 25 de Maio das demais escolas da rede pública que conhecem ou vivenciaram em experiências anteriores e elemento importante para garantir a vivência dos princípios da escola. A facilidade para estudar, morar na própria escola, dedicarse exclusivamente ao estudo no Tempo Escola, praticar no Tempo Comunidade o que se aprende na escola, exercitando a teoria e a prática e a aproximação entre 
escola e família, são apontados como elementos positivos pelos participantes da pesquisa.

A Pedagogia da Alternância surgiu na França em 1935 numa pequena comunidade rural denominada SèriganacPéboudou, conhecida como Maison Familiale (Escola Família Agrícola) existente até hoje na França. O objetivo da escola era criar possibilidades de forma coletiva para os jovens permanecerem no meio rural e não precisarem de forma individual migrar para a cidade. Esta pedagogia foi expandida para vários países do mundo, entre eles, o Brasil (Gimonet, 2007). De acordo com esta metodologia os estudantes permanecem um período na escola e um período em seus locais de origem. Estes distintos momentos se completam, sendo cada um uma continuidade do processo de formação do outro. De acordo com Gimonet (2007, p. 16), significa "um processo que parte da experiência da vida cotidiana (familiar, profissional, social) para ir em direção à teoria, aos saberes dos programas acadêmicos, para, em seguida, voltar à experiência, e assim sucessivamente".

Para Rafael ${ }^{\mathrm{ii}}$, um dos entrevistados, com a Pedagogia da Alternância a “(...) questão da aprendizagem é muito mais fácil, porque você não tem a preocupação de chegar da escola e ter que trabalhar.
Não precisa levantar às 5 h da manhã, pensar que se chover o ônibus não vai passar e vai perder aula”.

A relação entre teoria e prática, possibilitada pela Pedagogia da Alternância, é outro elemento que se repete na fala de todos os entrevistados. "No Tempo comunidade a gente gastava algum dinheirinho, mas tentava fazer alguma coisa prática. Eu fiz homeopatia, remédio prá carrapato. Comprei álcool e coisa. No fim só gastei dinheiro, mas valeu a pena. $\mathrm{O}$ que eu aprendi ninguém tira" (Egresso Rafael).

Após o Tempo Comunidade, ao retornar para a escola, os alunos apresentam um relatório e discutem sobre as dificuldades e práticas realizadas durante o Tempo Comunidade. De acordo com o Egresso Carlos: "Quando voltávamos para a Escola fazíamos um trabalho escrito, um relatório. Aí discutíamos sobre o que tinha acontecido no Tempo Comunidade. Em alguns momentos o coordenador do curso foi visitar o assentamento para conhecer melhor a nossa realidade".

Como evidenciam as falas dos egressos a relação entre teoria e prática é um dos principais elementos da proposta diferenciada da escola. $\mathrm{O}$ aluno não deixa de trabalhar quando está na escola e nem deixa de estudar quando está em sua 
localidade de origem. O trabalho como princípio educativo é vivenciado na prática. Além disso, a participação em tarefas do movimento sociais contribui para a formação dos sujeitos. "A gente participava das atividades do MST: Encontro Estadual, palestras, marchas. A gente se organizava para participar, discutia sobre o que estava acontecendo. Sempre tinha alguém dando uma palestra que acrescentava muito" (Egresso Rafael).

A fala de Rafael corrobora com a discussão realizada por Caldart (2000) sobre o elemento formativo existente na participação dos jovens nas ações do MST. Para a autora, a escola não é o único espaço de formação dos jovens engajados no MST, mas é um dos espaços onde as reflexões são realizadas. Assim, a escola é entendida como parte de um processo maior de formação, que inclui outras atividades.

A Egressa Carla também enfatiza a importância das atividades do MST das quais os alunos participaram durante o Ensino Médio e como isso contribuiu para a ampliação da compreensão sobre as contradições existentes na sociedade.

Participávamos pouco das atividades do MST pela intensidade do curso, mas fomos num fórum sobre biodiversidade em Curitiba, para o Congresso Nacional do MST em Brasília e promovemos um almoço no aniversário do MST- SC no dia 25 de Maio. Eu participava do MST mais nos tempos comunidade, orientada pela regional, além de entender que quando se necessita de uma coisa não adianta ficar em casa esperando que não vem. Participar das atividades do MST é um momento de formação, de entender as forças que nos reprimem, o ódio que a elite tem da classe trabalhadora. $\mathrm{O}$ quanto temos que lutar para nos transformar numa sociedade um pouco melhor (Egressa Carla).

Para além da sala de aula, a formação cultural e política dos alunos se dá também nos chamados Tempos Educativos. Trata-se de tempos destinados para a leitura de materiais produzidos pelos movimentos sociais, e mesmo livros sugeridos pela coordenação do curso. Após as leituras, são realizados debates em grupos de estudo para problematizar os temas.

A mística é um dos elementos apontados pelos egressos como espaço formativo. Trata-se de um ritual que faz parte da construção e reconstrução da identidade política e coletiva dos movimentos sociais do campo, realizados em eventos e escolas dos movimentos sociais do campo. Além desses momentos, os estudantes assistem a filmes, recebem cantores populares locais e de fora para apresentações culturais. "Participávamos das festas da comunidade e da feira da maçã na cidade, assistimos, por exemplo, o filme do Che, do golpe contra Hugo Chavez, alguns documentários sobre o problema dos 
agrotóxicos e do agronegócio entre muitos outros" (Egressa Carla).

A relação com a comunidade, no caso o assentamento onde está localizada a escola, também faz parte da formação. Ao valorizar a cultura local, os saberes dos mais velhos e a solidariedade, os alunos também aprendem.

As noites culturais a gente que preparava nos Núcleos de Base. Chamávamos as pessoas da comunidade para tocar gaita, violão, prá dançar. Às vezes a gente reunia um grupo de alunos e íamos à casa dos assentados ou dos professores que moravam no assentamento. Às vezes a gente ia à casa dos idosos limpar feijão, roçar. Eles tratavam bem a gente, diziam 'vem aqui pra gente conversar, a gente não tem ninguém pra conversar'. Eles tratavam nós bem, davam pão, café etc. Tinha época que a vaca da escola não dava leite e a gente ia na casa dos assentados tomar leite (Egresso Rafael).

\section{Como salienta Caldart (2008):}

(...) a Educação do Campo nasceu colada ao trabalho e à cultura do campo. E não pode perder isso em seu projeto. A leitura dos processos produtivos e dos processos culturais formadores (ou deformadores) dos sujeitos do campo é tarefa fundamental da construção do projeto político e pedagógico da Educação do Campo (p. 15).

A auto-organização dos alunos é outro elemento da proposta da Escola, facilitada pela Pedagogia da Alternância. A organização da rotina voltada para o trabalho coletivo, para a não distinção entre trabalho intelectual e manual, para a não diferenciação de trabalhos em relação ao gênero, são alguns aspectos formativos do processo de auto-organização. Por exemplo, os meninos que muitas vezes não tinham o hábito de lavar a louça e a roupa em suas casas, passam a fazê-lo na escola, processo formativo relevante diante da necessidade de superação das relações de opressão entre os gêneros.

A auto-organização dos alunos se dá através de Núcleos de Base (NBs). Trata-se de um espaço destinado para discussão, avaliação e encaminhamentos gerais da escola. Neste espaço, os alunos organizados em seus referidos NBs estabelecem o diálogo sobre assuntos referentes ao cotidiano da escola, bem como avaliam a participação dos integrantes do seu grupo em relação às decisões tomadas coletivamente.

Os educandos se organizavam em núcleos de base (grupos menores) para discutir os assuntos da escola (trabalho, estudo, convivência, indisciplina etc.) depois esses pontos eram discutidos na CNBT (Coordenação dos Núcleos de Base da Turma), ou em plenária na forma de assembleia, aí os coordenadores do curso participavam e nos ajudavam tomar as decisões. Os professores também se reuniam (mas não sei bem o que tratavam). Os pais e assentados que ajudaram a construir a escola faziam reuniões, mas com menor frequência (Egresso Cristiano). 
Rafael detalha como se dá a organização dos Núcleos de Base (NBs) e como as decisões eram tomadas de forma democrática na escola, com a participação efetiva de todos os alunos.

Toda segunda tinha reunião dos NBs onde se discutiam as questões que deviam ser levadas para a reunião de todos os núcleos. Todas as terçasfeiras tinha reunião com $\mathrm{o}$ Coordenador de cada NB, com a direção da escola e com os professores. Por exemplo, a gente queria assistir futebol na quarta à noite até mais tarde, queria ir num torneio de futebol, num baile, se tivesse algum problema de disciplina, de alimentação etc. tudo era conversado e decidido no coletivo. Após a reunião de terça a gente se reunia novamente para saber qual tinha sido a decisão tomada (Egresso Rafael).

De acordo com Alencastro (2009):

(...) a participação é um mecanismo de representação e participação política. A participação mobiliza professores, funcionários, alunos, pais e representantes da comunidade vinculados a processos de socialização educativa (p. 167).

A relação entre alunos, professores e direção, a clareza e o comprometimento de todos com o Projeto Político Pedagógico da Escola também são destaques no relato do Egresso Carlos, que hoje vive em São Paulo e estuda Educação Física.
Os professores não costumavam faltar por qualquer coisa. Não querer dar aula, isso nunca aconteceu. Aqui em São Paulo eu vejo que na escola da minha prima os professores falam prá não ir ninguém quando tem feriado no dia seguinte. Às vezes não vai a semana inteira na aula. Lá na 25 se algum professor tivesse algum problema familiar e faltava, tinha professores que moravam ao redor da escola e a gente nunca ficava sem aula. Os professores de biologia, filosofia, história, geografia moram lá. O diretor morava lá. A escola tinha estrutura para alguns professores que iam de fora $\mathrm{e}$ dormiam lá. Por exemplo, a gente teve aula de direito e o professor ficou lá com a gente. A maioria dos professores participava das nossas ações do MST. A maioria apoiava (Egresso Carlos).

Mesmo os professores mais distantes do Projeto Político Pedagógico da Escola ao se aproximarem da proposta educativa e conhecer sua história mais profundamente acabam se envolvendo, pois se deparam com uma organização não vivenciada em experiências anteriores em suas carreiras docentes, conforme nos elucida a fala da egressa Carla, que hoje é formada em Medicina Veterinária pelo PRONERA:

Geralmente o Estado mandava os professores que mais 'incomodavam' nas escolas da cidade, como, digamos assim, um castigo para eles. Quando chegavam à escola eram inseridos na nossa rotina, mas tinham autonomia para ministrar suas aulas. Acabavam, na maioria dos casos, se interessando e vivenciando a escola, atendendo também as demandas que eram solicitadas do curso técnico, para de 
alguma forma relacionar os conteúdos. Havia alguns poucos professores do assentamento como o M. e a N. que trabalharam algumas matérias do curso técnico, assim como técnicos e veterinários da assistência técnica do MST. Os demais professores do técnico eram da Escola Agrotécnica Federal de Rio do Sul e não entravam na questão política (Egressa Carla).

Carla afirma que os conteúdos foram bem desenvolvidos pelos professores, contudo, aponta que integração entre as diferentes áreas do conhecimento é um dos desafios a serem enfrentados pela Escola.

Acredito que os conteúdos foram bem trabalhados, porém, algumas coisas acabavam ficando para trás e outras passadas meio por cima, assim como na maioria das escolas públicas. Eu acho que os professores eram qualificados para trabalhar na disciplina que davam aula, não me lembro de nenhum caso diferente. A integração entre técnico e médio sempre foi um desafio, uma das poucas vezes que me lembro dessa integração foi a matemática, aprendemos medir área na prática, e nos ajudou muito na topografia. Mas é um aspecto que a escola deve seguir tentando melhorar (Egressa Carla).

Quanto às aulas, os alunos estudam em período integral no Tempo Comunidade e, esporadicamente, estudam nos três períodos. As aulas no período da noite eventualmente aconteciam quando os professores das disciplinas técnicas vinham de fora e tinham que aproveitar o tempo ao máximo.

Tínhamos de dois a três períodos de aulas, nos intervalos nos organizávamos para garantir as tarefas de sobrevivência, as que me lembro são: lavar louça do almoço e janta, fazer e servir café, limpar alojamento, tratar os porcos, coelhos e galinhas, molhar a horta. Essas atividades eram divididas por núcleos de base ou setores de trabalho. Isso ajuda a criar responsabilidade, espírito coletivo e ser organizado (Egresso Carlos).

O incentivo à pesquisa é outro elemento valorizado pela escola. Além dos relatórios apresentados ao final de cada Tempo Comunidade, no terceiro ano do Ensino Médio todos os alunos realizam um estágio e escrevem um Trabalho de Conclusão de Curso (TCC), que é apresentado posteriormente aos colegas, professores e em Encontros Estaduais do MST.

O Egresso Rafael fez estágio na Coopercontestado, uma das cooperativas do MST, localizada em Fraiburgo. Carla realizou o seu na Cooperativa de Industrialização de Leite dos Assentados da Região Oeste de SC (Cooperoeste). Carlos e Cristiano fizeram estágio nos seus próprios assentamentos. Tanto Carla como Rafael pesquisaram sobre a produção leiteira. 
Cada educando fez um estágio sobre um tema de seu maior interesse, e depois, um relatório de estágio, apontando seus aprendizados e a experiência que adquiriu. $\mathrm{O}$ meu tema foi qualidade do leite. A metodologia foi realizar visitas aos assentados e demais produtores da Cooperoeste, juntamente com os técnicos e veterinários da Cooperativa. Lá procurava junto a esses profissionais identificar os problemas da produção e qualidade do leite. No final escrevi o meu TCC tentando articular com o que tinha aprendido no curso (Egressa Carla).

A partir das falas dos egressos evidencia-se que a prática do Projeto Político Pedagógico da Escola 25 de Maio está inserida no debate mais amplo sobre as contradições que envolvem a relação campo-cidade. O que o conceito Educação do Campo apresenta de novo na história da educação é a tríade Campo - Políticas Públicas - Educação. É a relação entre estes três termos que caracteriza a Educação do Campo. O contexto que busca expressar é marcado por contradições (Caldart, 2008).

Como salienta Caldart (2008) o campo está em primeiro lugar na tríade CampoPolíticas Públicas-Educação, pois a Educação do Campo surgiu do campo, da sua dinâmica histórica, das suas contradições de classe, da luta pela terra, de seres humanos concretos. Em segundo lugar, a luta por escolas nos assentamentos e acampamentos do MST e a luta das comunidades camponesas para não perderem suas escolas, sua identidade e seus territórios e, em terceiro lugar, a educação como parte de um projeto de campo, não como lugar de negócio, mas lugar de construção de discussão e debate sobre a realidade, de forma e conteúdo que trate também das questões concretas vividas pelos seus sujeitos. Assim, tomar os termos separadamente significa promover uma desconfiguração política e pedagógica de fundo da Educação do Campo.

As falas dos egressos evidenciam as contradições, conflitos e capacidade organizativa dos estudantes através da participação na construção cotidiana do Projeto Político Pedagógico. A Educação do Campo abre também espaço para a experimentação do novo, do que é exemplo o envolvimento da escola com a construção de modelos alternativos de produzir e se relacionar com a terra, que engloba as relações campo-cidade, a partir da construção da agroecologia. Como ressaltam Medeiros \& Leite (2012) à medida que o termo agronegócio foi se consolidando como símbolo da modernidade, os movimentos sociais passam a contrapor o modelo agroecológico de produção, pautado na valorização da agricultura camponesa ou familiar e nos princípios da policultura, dos cuidados ambientais e do controle dos 
agricultores sobre a produção de suas sementes. Além disso, passam a expandir a crítica à concentração fundiária, a denunciar a matriz tecnológica do agronegócio pautada no uso de sementes transgênicas, no uso abusivo de agrotóxicos, na monocultura, voltado principalmente para a exportação de commodities agrícolas. Em síntese, ao modelo do agronegócio passa a ser contraposto o modelo agroecológico.

\section{Considerações finais}

Ao ser compreendida dentro da historicidade que a constituiu, a Educação do Campo busca a recomposição da relação entre educação e trabalho. Os diferentes tempos educativos permitem que o aluno se relacione com o trabalho e com a educação, problematizando a realidade a partir do conhecimento elaborado e abrindo espaço para a construção e experimentação de novas tecnologias, como a agroecologia.

A relação entre educação e trabalho que constitui o curso de Ensino Médio da Escola 25 de Maio é permeada pelas especificidades do trabalho no campo, dos modos de trabalhar na agricultura e da articulação entre conhecimentos científicos, tecnológicos e tradicionais, da própria realidade dos sujeitos dessa educação, os trabalhadores assentados rurais. A agroecologia é o que subsidia a formação técnica e também a formação política, uma vez que se insere no contexto em que os movimentos sociais passam a afirmar a agroecologia como contraponto ao agronegócio.

No que se refere aos conteúdos do currículo, a articulação entre conhecimentos básicos e técnicos a partir do mundo do trabalho, contemplando os conteúdos das ciências, das tecnologias e das linguagens (Kuenzer, 2009), ainda é um desafio na Escola 25 de Maio. Encontramos em algumas ementas de disciplinas certa articulação entre os conteúdos, mas nas falas dos egressos aparece a falta de canais mais efetivos para a integração entre os diferentes conhecimentos.

A pesquisa mostra que no seio das contradições é possível projetar e praticar formas de relação entre educação e trabalho que apontem para transformações mais amplas, desde a resistência dos trabalhadores do campo. A escola pensada nessa perspectiva de transformação terá que enfrentar o contexto adverso, permeado pelo individualismo e a competitividade.

Ao olharmos para a realidade da educação pública no país, podemos afirmar que a Escola 25 de Maio, ainda que dentro de certos limites, vem buscando consolidar 
a integração entre educação e trabalho. Frigotto (2013) analisando as políticas públicas voltadas para o Ensino Médio no Brasil afirma que "nos últimos cinquenta anos avançamos de forma pífia no aumento quantitativo e na qualidade dos jovens que cursam o Ensino Médio na idade adequada, e as políticas de formação profissional para a grande massa de jovens e adultos estão na lógica da improvisação, da precarização e do adestramento" (p. 3).

Diante do cenário descrito pelo autor, a Escola 25 de Maio está na contramão da realidade atual. Iniciando pelo fato de possuir um Projeto Político Pedagógico construído com a participação de vários sujeitos: assentados pais dos alunos; universidade; movimento social; estudantes; professores; gestores e secretaria de ensino. Dos conflitos entre estes diferentes sujeitos é que emerge e se constrói cotidianamente a proposta da Escola 25 de Maio para o Ensino Médio.

Entre os principais avanços da proposta de Ensino Médio da Escola 25 de Maio que podemos inferir a partir das relações estabelecidas pelos alunos egressos sobre a prática do Projeto Político Pedagógico destacamos: a articulação entre teoria e prática; a problematização das contradições existentes na sociedade; a apropriação de um tema atual, que é a agroecologia; criação das condições necessárias para a permanência dos jovens na escola através da Pedagogia da Alternância; aproximação entre família e escola; a formação de um coletivo de professores engajados na proposta da escola; o currículo que aproxima cultura, saberes locais e conhecimento científico, voltados para intervenção crítica e criativa na realidade e por fim, a grande novidade da Escola, que é a discussão sobre a agroecologia, pouco difundida ainda na educação brasileira. Este conjunto de elementos coloca a escola no lugar de resistência em um campo cada vez mais dominado como lugar de negócio e produção de mercadoria.

\section{Referências}

Alencastro, I. P. (2009). Projeto PolíticoPedagógico e gestão democrática: novos marcos para a educação de qualidade. Revista Retratos da Escola, 4(3), 163-171.

Burke, T. J. (1994). Fraiburgo do machado ao computador. Curitiba, PR: Gráfica Vicentina.

Caldart, R. S. (2000). Pedagogia do Movimento Sem Terra: escola é mais do que escola. Petrópolis, RJ: Vozes.

Sobre Educação do Campo. In Santos, C. A. (Org.). (2008). Educação do Campo: campo - políticas públicas educação. Brasília: INCRA/MDA.

Freitas, H. C. A. (2011). O curso técnico em agropecuária da Escola 25 de Maio: conflitos em torno da construção da 
proposta agroecológica. Revista Brasileira de Agroecologia. 6, 13-29.

Frigotto, G.; Ciavatta, M., \& Ramos, M.; (2009). Vocational Education and Development. In: UNESCO. International Handbook of Education for Changing World of Work. Bonn, Germany, UNIVOC, 1307-1319.

Frigotto, G., Ciavatta, M., \& Ramos, M. (2012). Ensino Médio Integrado: Concepção e contradições. São Paulo: Cortez.

Frigotto, G. (2013). Ensino Médio e técnico profissional: disputa de concepções e precariedade. Le Monde Diplomatique. http://www.diplomatique.org.br/artigo.php ?id=1384. Acesso em 13 de julho de 2016.

Kuenzer, A. (2001). Ensino de $2^{o}$ grau: o trabalho como princípio educativo. São Paulo, SP: Cortez.

. (2006). A educação profissional nos anos 2000: a dimensão subordinada

\footnotetext{
${ }^{\text {i }}$ A cidade também é uma grande produtora de mel são 15 mil colméias, que polinizam mais de 7 milhões de macieiras.

ii Os nomes dos egressos são fictícios respeitando o princípio do anonimato dos sujeitos da pesquisa.
}

das políticas de inclusão. Educação $e$ Sociedade, 27, 877-910.

- (2009). Ensino Médio: construindo uma proposta para os que vivem do trabalho. São Paulo, SP: Cortez.

Medeiros, L. S., \& Leite, S. P. (2012). Agronegócio. In Caldart, R. et. al. Dicionário da Educação do Campo. Rio de Janeiro e São Paulo, SP: Escola Politécnica Joaquim Venâncio e Expressão Popular.

Mohr, N. E. R., \& Mohr; M. F. (2007). Criação do curso técnico em agroecologia na Escola 25 de Maio: uma história coletiva de subversão à ordem. In Lenzi, L. H. C. et al. Formação de educadores em EJA no campo. Florianópolis: NUP/CED/UFSC.

Rodrigues, R. (2010). O Ensino Médio no Brasil: da invisibilidade à onipresença. In Caldart, R. (Org). Caminhos para transformação da escola: reflexões desde práticas da licenciatura em Educação do Campo. São Paulo, SP: Expressão Popular.

Recebido em: 01/07/2016

Aprovado em: 14/07/2016

Publicado em: 03/08/2016

Como citar este artigo / How to cite this article /
Como citar este artículo:
APA:
Kuhn, A. (2016). Ensino Médio Técnico em
Agroecologia e resistência no campo: o caso da
Escola 25 de Maio, Fraiburgo (SC). Rev. Bras. Educ.
Camp., 1(1), 107-127.
ABNT:
KUHN, A. Ensino Médio Técnico em Agroecologia
e resistência no campo: o caso da Escola 25 de Maio,
Fraiburgo (SC). Rev. Bras. Educ. Camp.,
Tocantinópolis, v. 1, n. 1, p. 107-127, 2016.

